Printed in Great Britain

\title{
SIZE VARIATIONS IN THE CYPRIDS OF SOME COMMON BARNACLES
}

\author{
By H. Barnes, D.Sc. \\ The Marine Station, Millport
}

(Text-figs. I-4)

In descriptive works on cirripede larvae some of the dimensions of the various developmental stages are often quoted as an aid to identification, and data have already been given in this form for Balanus balanoides, $B$. crenatus and Verruca stroemia (Pyefinch, I948a; Bassindale, I936; Runnström, 1925). There appear, however, to be no data on variations in size. The present account gives some observations on local variations, a discussion of which is a necessary preliminary to a study of regional variations and their significance.

\section{The Collection and Examination of the Material}

A number of different sampling methods have been used but most of the material has been collected by means of a Hardy Plankton Indicator (large model). The indicator was towed in the standard manner for a fixed distance (about I mile), the material being also collected for an investigation of annual changes in the barnacle population of this region. Such a method has the disadvantage that only one level is sampled, but other work has shown that the distribution of cyprids is fairly uniform between 0-20 metres. After completion of the tow the indicator was taken inboard, the plankton carefully washed off the silk into a bottle, and neutral formalin $(5 \%)$ added. The whole sample was counted and measured, the measurements being made by means of a calibrated eye-piece micrometer. These hauls were taken regularly throughout the spring and were also supplemented by net hauls: later in the year a number of net hauls were made, and opportunity was also taken of using material collected by $\mathrm{Mr} \mathrm{V}$. Bainbridge during the course of his own work.

Attention has been largely confined to the cyprid stage, since this can be more easily and more accurately measured, but some nauplii have been measured. Results are presented for three species, Balanus balanoides, $B$. crenatus and Verruca stroemia, collected over the varying periods. The total length and the greatest width were measured with the cyprid lying on its side. Attention will primarily be concentrated on the lengths; but similar deductions can be made using the width measurements. In the stage VI total length and greatest width of the carapace were measured with the animal lying on its ventral surface. The scale of magnification was 50 eye-piece units $=\mathrm{I} \cdot 02 \mathrm{~mm}$, 
but it will be more convenient in the discussion of the results to refer to the arbitrary units. All the material was preserved in neutral formalin $(5 \%)$, and strictly speaking the measurements refer only to animals preserved in this way.
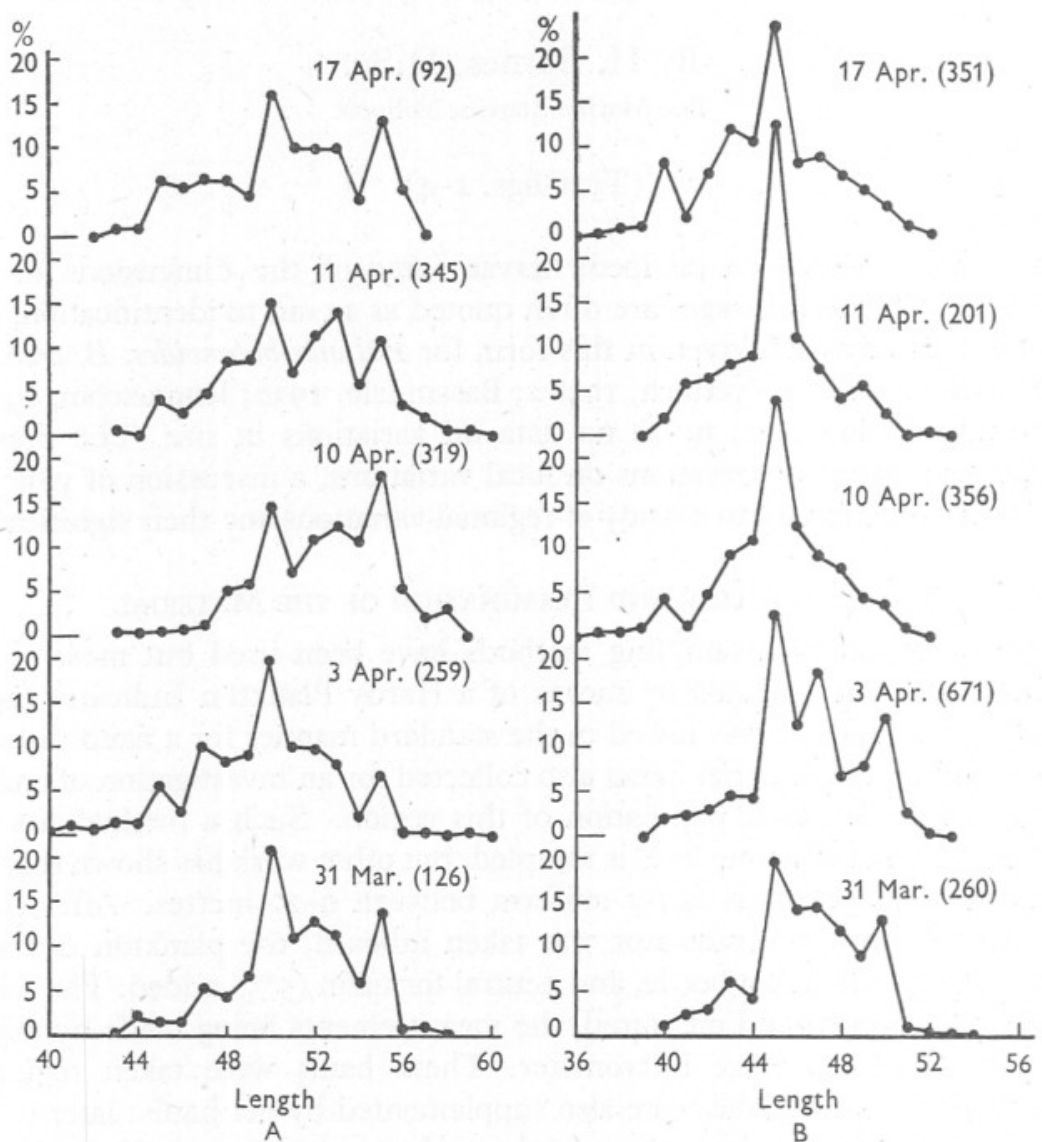

Fig. I. Size-frequency distribution of Balanus sp. cyprids in a series of hauls through the spring. Length in eye-piece units. Dates and numbers in collections are given. A, B. balanoides; B, B. crenatus.

\section{The SPRING OUtbuRST OF BALANUS BALANOIDES AND BALANUS CRENATUS}

The results for the cyprids of these two species are shown in Fig. I, which gives the size-frequency curves together with the numbers of the animals measured, and the dates of collection. Even if the minor peaks are neglected it is clear that with both species these size-frequency curves exhibit a number of modes, which are to be presumed to correspond to a number of populations of the cypris stage each with its own mean size. 
In B. balanoides the mode which is found at 50 units is present and well marked throughout the whole of the sampling period. A mode at 55 units is quite well marked in some of the samples, and there is a suggestion of other modes at intermediate points. In the earliest sample the 50-unit mode represents some $35 \%$ of the total frequency and is stronger than in the later samples. There is a tendency for the second mode at 55 units to be greater in strength later in the season. A study of the cumulative frequency curves supports the above deductions, but in view of the considerable overlap in the sizes they are not easy to analyse with certainty. It seems reasonable to suggest, however, that there are at any rate two distinct populations and that these are present throughout the season.

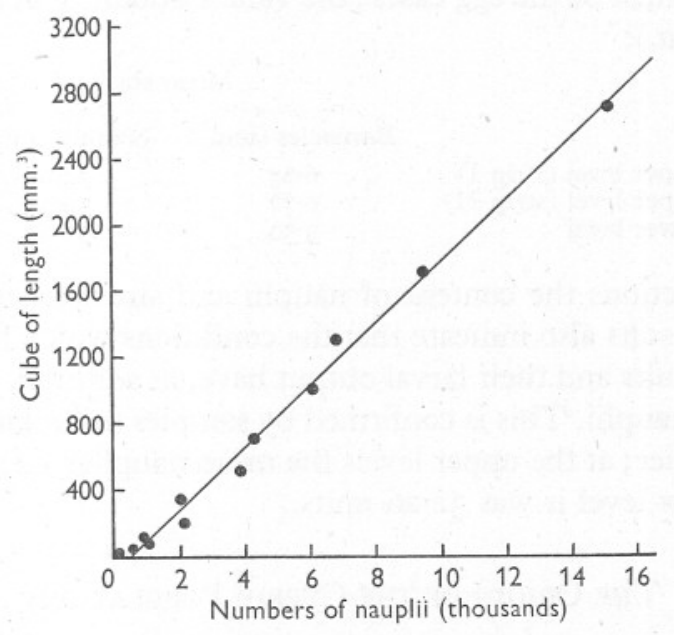

Fig. 2. Larval output and size of adults in B. balanoides. The total number of nauplii is plotted against the cube of the adult length. Grouped values are used.

In $B$. crenatus two modes are also present in the earlier samples, both quite strong, but as the season progresses the population giving rise to the higher modes disappears. This can only mean that one of the populations (larger size) concerned is produced only at the beginning of the season, whilst the other population is produced continuously throughout the season.

\section{The ENVIRONMENT AND REPRODUCTION}

Moore (1935) has shown that the number of larvae produced by a barnacle is a function of its size, a fact confirmed in this investigation. Fig. 2 shows a plot of the mean nauplii content for a series of size-groups against the cube of the length, which is approximately a linear function of the volume. It has also been shown (Moore, 1934; Barnes \& Powell, 1953) that the size attained by the adult barnacle at any given time is a function of a whole complex of 
conditions. However, since the conditions of the environment have such a marked influence on the growth-rate and on the reproductive capacity, it is important to examine whether they also affect the size attained by the nauplii at the time of extrusion. It has been possible to measure the size of ripe nauplii of known age at various levels on the shore. During his work on algal colonization Mr Powell had completely cleared a number of rocky strips of barnacles and other organisms, and a number of I-year-old barnacles were collected from the upper and lower levels on these strips on which zonation was just developing at the time of the spring outburst. These adults were all ripe and the embryos were teased out under water, when every time some nauplii escaped from the egg cases. The total length of a number of nauplii was measured whilst in the egg cases; the values obtained were as follows (50 units $=0.423 \mathrm{~mm}$.):

\begin{tabular}{lcc} 
& \multicolumn{2}{c}{ Mean size } \\
Upper level (strip I) & $\overbrace{\text { Narnacles (mm.) }}$ & Nauplii (units) \\
Upper level (strip II) & 6.67 & 34.65 \\
Lower level & 6.72 & 34.73 \\
Sow & 3.50 & 33.61
\end{tabular}

In these collections the content of nauplii and size were again correlated, and the above results also indicate that the conditions which have affected the growth of the adults and their larval output have, in addition, affected the size attained by the nauplii. This is confirmed by samples (of unknown age-group) taken from the pier; at the upper levels the mean naupliar size was 34.94 units and at a very low level it was $32 \cdot 26$ units.

\section{The Origin of the Cyprid Populations}

Cyprid populations may come to be different in size from more than one possible cause. The populations may represent different races, that is, be genotypic in origin. In view of the extensive mixing of the cyprids in the surface waters during the planktonic phase and their ultimate distribution over the whole intertidal zone in B. balanoides, together with the necessity for cross-fertilization, it seems unlikely that distinct races of adults giving rise to populations of different-sized cyprids would be developed. Further, when the frequency curve for the length/breadth ratio is plotted it is almost unimodal, in marked contrast to those for the length or breadth, suggesting that the populations are only different in size and not in shape (Fig. 3). Again, the populations may exhibit growth differences as a result of the effect of the environment during the planktonic development. The persistence of the separate populations in $B$. balanoides throughout the spawning season and the existence of differences in the nauplii within the ripe adults from different levels tends to negate this suggestion.

A more plausible suggestion is that in $B$. balanoides the modes represent the 
product of the different zones of the shore, for, in view of the above results, if the nutritive conditions are sufficiently well defined in the different zones there will be a tendency to produce a series of different-sized nauplii giving rise to different-sized cyprids which correspond to these levels with, of course, overlapping. Evidently, with $B$. balanoides, the upper and lower zones of the shore are sufficiently different to give this result, the environment and growth conditions at the two levels being sufficiently distinct. The growth-rate of $B$. crenatus also has been shown to vary according to the habitat, being far

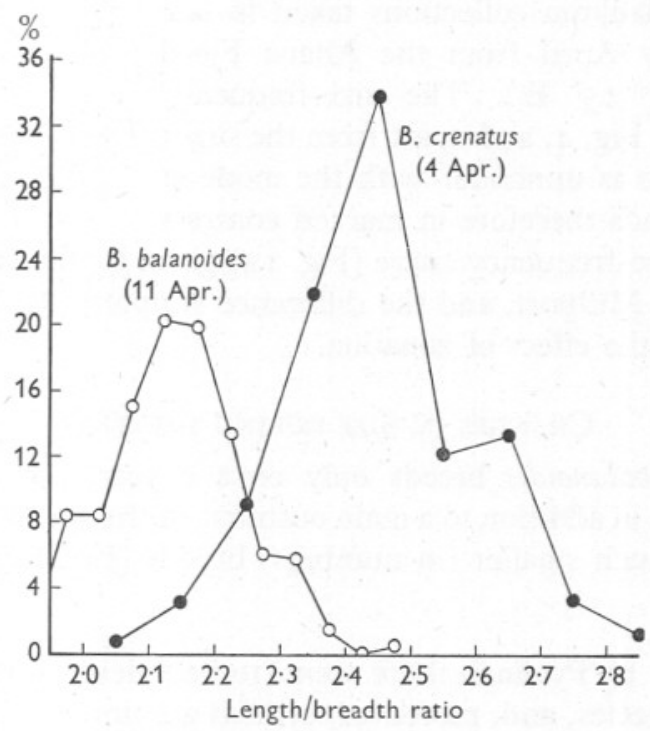

Fig. 3. Size-frequency of length/breadth ratio for B. balanoides and B. crenatus, for samples taken on II April and 4 April respectively. Grouped values are used. Compare with curves in Fig. I.

greater under the more favourable conditions (Barnes \& Bagenal, I95I; Barnes \& Powell, I953); but since this species is largely sublittoral in this region it is less clear why two distinct populations are produced. Perhaps those adults which just extend into the littoral and near-littoral zone are responsible for one population, whilst the deeper water populations produce the other. If this is so, since the major population of $B$. crenatus adults is certainly sublittoral, the near-littoral group must produce the larger cyprids, which constitute the smaller proportion of the total population (taken over the whole sampling period), and the sublittoral population must continue to spawn over a longer period, for the larger mode tends to disappear in the later collections (see Fig. IB). It is, however, possible that the populations correspond to the products of the different year-classes of adults. 


\section{The Size Distribution of Swedish BaLANUS BALANOIDES}

The tidal rise and fall at Millport is of the order of $\mathrm{ro} \mathrm{ft}$., sufficient to give large changes in environment with distinct algal zonation, and to give rise to at least two populations. On the west coast of Sweden the tidal rise is $\mathrm{I} \mathrm{ft}$. or less and on the preceding hypothesis only a single-sized population of cyprids might be expected. Through the kindness of Dr Höglund it has been possible to examine some plankton collections taken in late March and early April from the Altane Fjord $\left(58^{\circ} 45^{\prime}\right.$ N., II ${ }^{\circ}$ I $5^{\prime}$ E.). The size-frequency curve is given in Fig. 4, and apart from the slight break at 53 units is unimodal with the mode at 56 units. It stands therefore in marked contrast

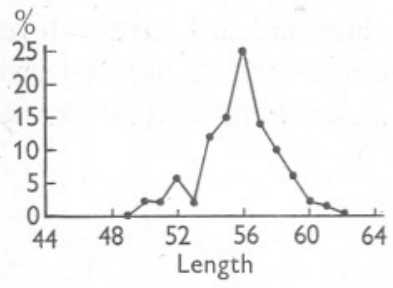

Fig. 4. Size-frequency distribution of Swedish B. balanoides. Length in arbitrary units. to the type of size-frequency curve (Fig. IA) given by the same species from British waters at Millport, and the difference supports the hypothesis given above regarding the effect of zonation.

\section{Changes in Size DURING THE YeaR}

At Millport $B$. balanoides breeds only once a year, but $B$. crenatus and Verruca stroemia, in addition to a main outburst in the spring, produce several later although much smaller (in numbers) broods (Pyefinch, I948).

\section{Verruca stroemia}

As pointed out by Pyefinch there seems to be a delay in the production of cyprids of this species, and, moreover, cyprids are never caught in quantities comparable with the nauplii, in surface or subsurface collections. However, small collections were obtained in both spring and autumn and have been examined. As far as can be determined from the smaller numbers ( 62 in each set, pooled samples from several days) the size-frequency curves for both collections are unimodal; and, since this is a genuine sublittoral species of fairly restricted habitat where conditions are uniform, this finding affords additional support for the previous hypothesis with regard to the other species. The mean lengths and their standard errors are given below for the spring and autumn cyprids:

$\begin{array}{lcccc} & \text { Mean length } & \text { S.E. } & \text { Ratio, L/B } & \text { S.E. } \\ \text { Spring } & 30 \cdot 8 & 0.163 & 2 \cdot 34 & 0.0196 \\ \text { Autumn } & 27.70 & 0.190 & 2 \cdot 33 & 0.0185\end{array}$

\section{Balanus crenatus}

Only comparatively few (27) were obtained during the autumn, insufficient for adequate representation of a size-frequency curve. They have therefore been compared with the unimodal spring curves. Since it is the smaller-sized 
mode that persists, any size decrease during the season will tend to be minimized:

\begin{tabular}{lcccc} 
& Mean length & S.E. & Ratio, L/B & \multicolumn{1}{c}{ S.E. } \\
Spring & 46.36 & $0 . \mathrm{II} 7$ & $2 \cdot 47$ & 0.00695 \\
Autumn & $4 \mathrm{I} \cdot 93$ & 0.399 & 2.46 & 0.0267
\end{tabular}

In both these species, therefore, which produce more than one brood a year, there is a significant decrease in size in the cyprids of the later broods although, as far as can be judged from the length/breadth ratios, there is no change in shape.

Size variations in successive broods during a year have often been reported for copepods (see, for example, Marshall, 1933, 1949) and both temperature and food are considered to be important factors. In general, larger animals are found when development takes place more slowly at lower temperatures. However, it has often been difficult to reconcile the facts with the actual changes in temperature. It is suggested that the rate of development of the eggs or of the embryos within the parent may be as important a factor as the rate of development during the planktonic stages in determining the size of any given stage. This might explain to some extent the unexplained fluctuations found by Marshall in the sizes of copepod stages, since although water temperatures in general rise during the summer, if size is to some extent determined by the rate of development, temperature fluctuations acting over a much shorter time could be important.

In the case of $B$. crenatus, considered above, development of the spring brood of nauplii takes place during the autumn and winter months, October to March, from eggs fertilized in the autumn. Development of the embryos is therefore slow and occurs during the period when the sea temperatures are low. Development of the autumn brood is more rapid, affected by higher temperatures. The brood may even be produced, according to Pyefinch (I948 b), from animals settled in the same spring; in consequence, on the above hypothesis, the nauplii and hence the cyprids so produced, would be expected to be smaller.

Thanks are due to Dr Höglund for providing the Swedish samples, to $\mathrm{Mr}$ V. Bainbridge for allowing the cyprids to be used from some of his collections, and to $\mathrm{Mr} \mathrm{H}$. T. Powell for providing the barnacles of known ages from his rock strips.

\section{SUMMARY}

The sizes, length and breadth, of the cyprids of Balanus balanoides, B. crenatus and Verruca stroemia have been measured on material collected during the spring outburst and in the later part of the year.

The size-frequency curves for Balanus balanoides and $B$. crenatus show at least two distinct modes during the spring, equivalent to populations of two 
distinct sizes. It is suggested that these correspond to populations developed in different environments. Measurements of the nauplii taken from adults at different points on the shore indicate that the size of the nauplii is dependent to some extent upon the conditions of development, the conditions also affecting growth and total nauplii output.

Swedish samples, in which the parents had developed under more uniform conditions, showed only a single population as regards size.

In B. crenatus and Verruca stroemia, which produce further broods during the year, the size decreases in these later broods. The rate of development of the eggs and embryos, probably dependent upon temperature, is suggested as the important factor.

\section{REFERENCES}

BARNES, H. \& BAGENAL, T. B., I95I. Observations on Nephrops norvegica (L.) and on an epizoic population of Balanus crenatus Brug. Fourn. Mar. Biol. Assoc., Vol. 30, pp. $369-80$.

Barnes, H. \& Powell, H. T., 1953. The growth of Balanus balanoides (L). and B. crenatus Brug. under varying conditions of submersion. fourn. Mar. Biol. Asșoc., Vol. 32, pp. 107-27.

Bassindale, R., I936. The developmental stages of three English barnacles, Balanus balanoides (Linn.), Chthamalus stellatus (Poli) and Verruca stroemia (O. F. Müller). Proc. Zool. Soc. Lond., I936, pp. 57-74.

MARShall, S. M., I933. On the biology of Calanus finmarchicus. II. Seasonal variations in the size of Calanus finmarchicus in the Clyde Sea Area. Fourn. Mar. Biol. Assoc., Vol. 19, pp. III-38.

- 1949. On the biology of the small copepods in Loch Striven. Fourn. Mar. Biol. Assoc., Vol. 28, pp. 45-I22.

Moore, H. B., I934. The biology of Balanus balanoides. I. Growth rate and its relation to size, season and tidal level. Fourn. Mar. Biol. Assoc., Vol. I9, pp. 85I-68.

- I935. The biology of Balanus balanoides. IV. Relation to environmental factors. fourn. Mar. Biol. Assoc., Vol. 20, pp. 263-77.

Pyefinch, K. A., I948 a. Methods of identification of the larvae of Balanus balanoides (L.), B. crenatus Brug. and Verruca stroemia O. F. Müller. Fourn. Mar. Biol. Assoc., Vol. 27, pp. 45I-63.

_ 1948b. Notes on the biology of cirripedes. Fourn. Mar. Biol. Assoc., Vol. 27, pp. $464-503$.

RunNSTRÖM, S., 1925. Zur Biologie und Entwicklung von Balanus balanoides (Linné). Bergens Mus. Aarbok., Naturv. Raekke, Nr. 5. 